\title{
Efficacy and safety of azithromycin and amoxicillin/clavulanate for otitis media in children: a systematic review and meta-analysis of randomized controlled trials
}

\author{
Gabriel Dawit ${ }^{*}$, Solomon Mequanent ${ }^{2}$ and Eyasu Makonnen ${ }^{1,2}$
}

\begin{abstract}
Background: Resistance, prolonged therapy, and more adverse reactions made amoxicillin less preferred for treating otitis media. This study aimed to compare the efficacy and safety of azithromycin and amoxicillin/clavulanate for the treatment of otitis media in children.

Methodology: This study was a systematic review and meta-analysis. PubMed, Cochrane library, and Google scholar databases were searched. Comparative randomized clinical trial studies between azithromycin and amoxicillin/ clavulanate to treat otitis media in children published up to 30 September 2019 were included. The risk of bias was assessed and Data was extracted by the first author and checked by the second author. Meta-analysis was performed by STATA software version 16, and Mantel-Haenszel statistical method with effect measure odds ratio was employed for analysis.

Result: 751 records were identified and 14 studies were eligible for analysis. In 12 studies azithromycin had equivalent clinical efficacy and 2 had less to amoxicillin/clavulanate. Meta-analysis results showed no statistically significant difference in efficacy in favor of amoxicillin/clavulanate after completion of treatment OR $0.75,95 \% \mathrm{Cl}(0.62-0.91)$. On subgroup analysis for children less than 2 years (OR $0.9695 \% \mathrm{Cl}(0.49-2.29)$, and greater than 2 years (OR $1.4095 \% \mathrm{Cl}$ (0.93-2.11) and also efficacy on follow up (OR $0.9795 \% \mathrm{Cl}(0.83-1.15)$ there is no statistically significant difference. The clinical adverse events are more in the amoxicillin/clavulanate group than in the azithromycin with a statistical significant difference OR 0.46 95\% Cl (0.43-0.56).
\end{abstract}

Conclusion: Azithromycin is comparable to amoxicillin/clavulanate to treat otitis media in children, and it is safer and more tolerable.

Keywords: Azithromycin, Amoxicillin/clavulanate, Otitis media, Meta-analysis, Systematic review

*Correspondence: gabrieldawit@gmail.com

${ }^{1}$ Center for Innovative Drug Development and Therapeutic Trials

for Africa (CDT Africa), College of Health Sciences, Addis Ababa University, Addis Ababa, Ethiopia

Full list of author information is available at the end of the article

\section{Introduction}

Otitis media is a middle ear infection, which exists in acute or chronic state and occur with or without symptoms caused by bacteria or virus [1]. About $80 \%$ of children have acute otitis media (AOM) once before the age of 3 years, and about $40 \%$ have six or more recurrences

(c) The Author(s) 2021. This article is licensed under a Creative Commons Attribution 4.0 International License, which permits use, sharing, adaptation, distribution and reproduction in any medium or format, as long as you give appropriate credit to the original author(s) and the source, provide a link to the Creative Commons licence, and indicate if changes were made. The images or other third party material in this article are included in the article's Creative Commons licence, unless indicated otherwise in a credit line to the material. If material is not included in the article's Creative Commons licence and your intended use is not permitted by statutory regulation or exceeds the permitted use, you will need to obtain permission directly from the copyright holder. To view a copy of this licence, visit http://creativeco mmons.org/licenses/by/4.0/. The Creative Commons Public Domain Dedication waiver (http://creativecommons.org/publicdomain/ zero/1.0/) applies to the data made available in this article, unless otherwise stated in a credit line to the data. 
by the age of 3 years [2, 3]. Bacteria isolates $50 \%$ to $90 \%$ from middle ear fluid culture with cases of acute otitis media and otitis media with effusion [4]. The three most common bacteria which cause otitis media are Streptococcus pneumoniae, Haemophilus influenzae, Moraxella catarrhalis [5-7]. A systematic review done by DeAntonio et al. reported the incidence of otitis media under 6 years old from five countries; $9.2 \%$ in Nigeria, $10 \%$ in Egypt, 6.7\% in China, 9.2\% in India, 9.1\% in Iran, and $7.8 \%$ in Russia [8]. Severe otitis media can cause medical complications, like mastoiditis, subperiosteal abscess, facial nerve palsy brain abscesses, meningitis, and chronic sinus infection $[9,10]$. Otitis media have also an impact on childhood development: frequent occurrence of conductive hearing loss in less than 2 years of life has a negative effect on the development of the central auditory nerve pathways [11]. This effect results in deficits in auditory skills like attention, sound discrimination, the ability to listen for competing noise, and auditory memory [11]. These problems result delays in verbal language, intellectual development, and social skills.

Amoxicillin and other beta-lactam antibiotics considered standard treatments for otitis media are becoming less effective due to resistance emergence. Bacteria and viruses are responsible for otitis media and beta-lactams are active against bacteria only, but Azithromycin has antibacterial, antiviral, and anti-inflammatory activity. This study aimed to compare the efficacy and safety of azithromycin and amoxicillin/clavulanate for the treatment of otitis media in children from comparative randomized clinical trials through systematic review and meta-analysis.

\section{Methodology}

\section{Study design and eligibility criteria}

This study design is a systematic review and meta-analysis. The studies included are only randomized clinical trials conducted in children from 6 months to 15 years old with otitis media. Identified studies are included in the review if they met the following inclusion criteria:

1. A randomized clinical trial study for comparison of azithromycin and amoxicillin/clavulanate for treating any type of otitis media.

2. A randomized clinical trial study with clinical outcome cure and improve or failure from otitis media.

3. Participants of the study are children age ranged from 6 months up to 15 years.

4. Children with clinical evidence of bilateral or unilateral infection of the middle ear (OM).

5. Published article up to 30-09-2019.

6. A full-text article for review.

7. Articles written in English.

\section{Search strategy and data extraction}

This review was designed according to the preferred reporting items for systematic reviews and meta-analysis protocols (PRISMA) guidelines [12]. Two databases (PubMed and Cochrane library) and manual search from Google Scholar were used to search the studies. Published research papers were systematically and comprehensively searched. All the search results from PubMed, Cochrane library and Google scholar were stored in Mendeley reference management software, and the duplicates were removed by the software. Both reviewers screened the title and abstract of each article depending on the PICOs criteria independently then checked for the eligibility criteria.

The data extraction form was developed with the help of the Cochrane collaboration data extraction form for interventional review for RCTs and Non-RCTs. All the available data were extracted with the extraction form. One author extracted the data from the included studies and the second author checked the extracted data. All disagreements were resolved by discussion between the two authors. The extracted data were stored in a Microsoft Excel spreadsheet.

\section{Data quality assessment}

For each article, the following were critically appraised independently by two reviewers.

- Whether the study design or approach was appropriate to the research question.

- Whether outcome measure was valid and appropriate to the research question.

- The risk of bias in the study design and results were assessed by the Cochrane risk of bias tool-2 (ROB-2).

\section{Data analysis and synthesis}

The findings of individual eligible and quality-assured studies were collated and summarized. Meta-analysis was performed using STATA software version 16 and Mantel-Haenszel statistical method and effect measure odds ratio was employed for data analysis, data synthesis, and creating tables (forest plot). Meta-analysis was performed for studies with a similar design on the same intervention and assessing same outcome and where sufficient data were available. The results were reported in an odds ratio with $95 \% \mathrm{CI}$ in studies. Heterogeneity $\mathrm{I}^{2}$ was analyzed from the forest plot result and publication bias was also assessed by creating a funnel plot. We used a random and fixed effects model depending on the degree of heterogeneity between studies. Results, together with the 
associated interpretations and conclusions were generated from narrative and quantitative synthesis, and the review was presented on a table.

\section{Results}

From the three databases, 751 records, PubMed 539, Cochrane library 85, Google Scholar 127 (manual search) were identified. All search results were stored in Mendeley reference manager software. 67 duplicates were removed by the reference software Mendeley. In the first phase of title and abstract screening, 658 studies were excluded for not meeting PICOs criteria. Twenty

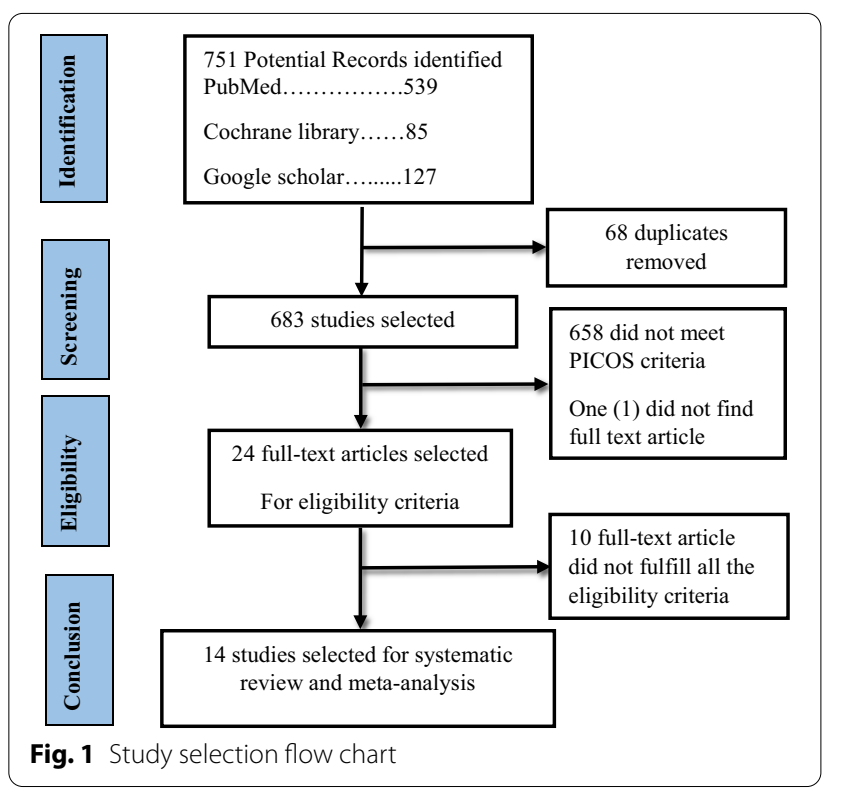

four full-text articles full-filled the PICOs criteria out of which only 14 studies full filled the eligibility criteria to be included in the present systematic review and Meta-analysis. All the included studies were comparative randomized studies on azithromycin and amoxicillin/clavulanate of age range from 6 months to 15 years children. These 14 comparative RCTs were conducted in four continents and more than 22 countries with 226 centers of a total sample size of 5600 children. None of these studies was conducted in Africa and Australia and most were conducted in the US (Fig. 1).

\section{Data quality assessment}

All the 14 studies were critically appraised independently by the two reviewers. In all 14 eligible RCTs, the study design and outcome measure was valid and appropriate to the research questions. The risk of bias in the study design and results were assessed by the revised tool Cochrane risk of bias in randomized trials (RoB 2) latest version 22 August 2019. The overall risk of bias of individual study is shown in Table 1.8 studies were found to be low risk of bias and 6 were with some concern of bias but none of the studies was with a high risk of bias.

\section{Efficacy evaluation}

The efficacy evaluation for fourteen studies after completion of treatment between the tenth to sixteenth days following initiation of treatment in the twelve studies, there was no statistically significant difference in the efficacy of azithromycin and amoxicillin/clavuluanate (Table 2). The efficacy assessment on long term

Table 1 Summary risk of bias of studies (ROBs-2)

\begin{tabular}{|c|c|c|c|c|c|c|}
\hline S no. & Author (year) & $\begin{array}{l}\text { Bias due to deviations } \\
\text { from intended } \\
\text { interventions }\end{array}$ & $\begin{array}{l}\text { Bias from } \\
\text { missing outcome } \\
\text { data }\end{array}$ & $\begin{array}{l}\text { Bias in the } \\
\text { measurement } \\
\text { of the } \\
\text { outcome }\end{array}$ & $\begin{array}{l}\text { Bias in selection } \\
\text { of the reported } \\
\text { results }\end{array}$ & $\begin{array}{l}\text { The overall risk of } \\
\text { bias }\end{array}$ \\
\hline 01 & Daniel (1993) & Some concern & Lower risk & Lower risk & Lower risk & Some concerns \\
\hline 02 & Schaad (1993) & Some concern & Lower risk & Lower risk & Lower risk & Some concerns \\
\hline 03 & Principi (1995) & Some concern & Lower risk & Lower risk & Lower risk & Some concerns \\
\hline 04 & Arguedasa et al (1996) & Lower risk & Lower risk & Lower risk & Lower risk & Low risk \\
\hline 05 & Gerson (1996) & Some concern & Lower risk & Lower risk & Lower risk & Some concerns \\
\hline 06 & Mohini (1996) & Some concern & Lower risk & Lower risk & Lower risk & Some concerns \\
\hline 07 & Samuel (1996) & Lower risk & Lower risk & Lower risk & Lower risk & Low risk \\
\hline 08 & Dagan (2000) & Lower risk & Lower risk & Lower risk & Lower risk & Low risk \\
\hline 09 & Arrieta et al. (2003) & Lower risk & Lower risk & Lower risk & Lower risk & Low risk \\
\hline 10 & Block et al. (2003) & Lower risk & Lower risk & Lower risk & Lower risk & Low risk \\
\hline 11 & Dune et al. (2003) & Lower risk & Lower risk & Lower risk & Lower risk & Low risk \\
\hline 12 & Hoberman et al. (2005) & Lower risk & Lower risk & Lower risk & Lower risk & Low risk \\
\hline 13 & Guven et al. (2006) & Some concern & Lower risk & Lower risk & Lower risk & Some concerns \\
\hline 14 & Arguedas et al. (2011) & Lower risk & Lower risk & Lower risk & Lower risk & Low risk \\
\hline
\end{tabular}


Table 2 Included studies with their major findings

\begin{tabular}{|c|c|c|c|c|c|}
\hline Author (year) & $\begin{array}{l}\text { Target population age } \\
\text { range (Children) }\end{array}$ & Study place & Sample size & $\begin{array}{l}\text { Clinical success } \\
\text { \%Azithromycin/ } \\
\text { amoxicillin-clavulanate }\end{array}$ & P-value $(95 \% \mathrm{Cl})$ \\
\hline Daniel (1993) & (2-8 year) with $\mathrm{OM}$ & Europe Multi center & 159 & $99 \% / 100 \%$ & NS (N/A) \\
\hline Schaad (1993) & $\begin{array}{l}6 \text { months to } 12 \text { years with } \\
\text { AOM }\end{array}$ & Switzerland & 389 & $93.2 \% / 97.4 \%$ & NS (N/A) \\
\hline Principi (1995) & $\begin{array}{l}\text { (6-months to } 12 \text { years) with } \\
\text { OM }\end{array}$ & $\begin{array}{l}\text { Brazil, Chile, Germany, } \\
\text { Italy, Korea, Spain, Turkey } \\
\text { Venezuela }\end{array}$ & 483 & $92.6 \% / 93.9 \%)$ & NS (N/A) \\
\hline Arguedasa et al. (1996) & $\begin{array}{l}\text { 6-months to } 12 \text { years with } \\
\text { OM with effusion }\end{array}$ & San Jose Costa Rica & 100 & $82.5 \% / 78.9 \%)$ & NS (N/A) \\
\hline Gerson (1996) & $\begin{array}{l}2 \text { to } 15 \text { years with Acute otitis } \\
\text { media }\end{array}$ & USA & 169 & $87.7 \% / 100 \%$ & $0.102(\mathrm{~N} / \mathrm{A})$ \\
\hline Mohini (1996) & $\begin{array}{l}\text { (6-months to } 12 \text { years) with } \\
\text { Acute otitis media }\end{array}$ & USA & 527 & $92.3 \% / 90 \%$ & 0.417 (N/A) \\
\hline Samuel (1996) & 1 to 15 years with $\mathrm{AOM}$ & USA & 677 & $87.6 \% / 87.9 \%$ & $0.636(\mathrm{~N} / \mathrm{A})$ \\
\hline Dagan (2000) & $\begin{array}{l}6 \text { months to } 2 \text { years with } \\
\mathrm{AOM}\end{array}$ & $\begin{array}{l}\text { Israel USA and Dominican } \\
\text { Republic }\end{array}$ & 238 & $70 \% / 85.7 \%$ & $0.023(2,30)$ \\
\hline Arrieta et al. (2003) & $\begin{array}{l}\text { 6-months to } 6 \text { years with } \\
\text { recurrent or persistent } \\
\text { AOM }\end{array}$ & USA, Latin American centers & 304 & $85.9 \% / 84.1 \%)$ & $0.744(-6.4,10)$ \\
\hline Block et al. (2003) & $\begin{array}{l}\text { (6-months to } 12 \text { years) with } \\
\text { AOM }\end{array}$ & USA & 350 & $86.9 \% / 87.7 \%$ & NS $(-9.2,6.5)$ \\
\hline Dune et al. (2003) & $\begin{array}{l}\text { (6-months to } 12 \text { years) with } \\
\text { AOM }\end{array}$ & USA & 373 & $82.7 \% / 88.3 \%$ & $0.186(-13,3)$ \\
\hline Hoberman et al. (2005) & $\begin{array}{l}6 \text { month to } 30 \text { month with } \\
\text { AOM }\end{array}$ & $\begin{array}{l}\text { USA. Bulgaria, Chile, Domen- } \\
\text { ica Republic, Guatemala, } \\
\text { Israel, Peru, Romania Latvia } \\
\text { Mexico, }\end{array}$ & 731 & $80.9 \% / 90.5 \%$ & $<0.01(2.37,17)$ \\
\hline Guven et al. (2006) & $\begin{array}{l}\text { (6-months to } 12 \text { years) with } \\
\text { AOM }\end{array}$ & Turkey & 180 & $100 \% / 100 \%$ & $0.24(\mathrm{~N} / \mathrm{A})$ \\
\hline Arguedas et al (2011) & 3 months -4 years with $\mathrm{AOM}$ & $\begin{array}{l}\text { North America, Europe, and } \\
\text { Latin America }\end{array}$ & 923 & $80.2 \% / 84.5 \%$ & $0.24(-10.4,2.6)$ \\
\hline
\end{tabular}

NS, non-significant; N/A, not-available; AOM, acute otitis media; OM, otitis media

follow-up between 3 and 5 weeks in eleven studies, the clinical [13-19] and bacteriological [20-22] efficacies were comparable with no statistically significant difference in ten of the studies, but the bacteriological efficacy of azithromycin was inferior to that of amoxicillin/ clavulanate in one study [23]. The sub-group analysis was reported in five studies. In children less than or equal to two and greater than 2 years old, there was no statistically significant difference between azithromycin and amoxicillin/clavulanate groups in clinical [15, 18, 19, 24] and bacteriologic [22] efficacy. From the meta-analysis, the overall efficacy, i.e., both clinical and bacteriological efficacies, of the two treatments after completing treatment in the first assessment had little significant difference with OR $=0.7595 \%$ CI $(0.62-0.91)$ (Fig. 2) and on second assessment no significant difference with OR $=0.97$; 95\% CI (0.83-1.15) (Fig. 3). In subgroup meta-analysis, the overall effect between the groups in less than two and greater than 2 years children had no statistically significant difference with
$\mathrm{OR}=0.96 ; 95 \% \mathrm{CI}(0.41-2.29)$ (Fig. 4) and $\mathrm{OR}=1.40$ 95\% CI [0.93-2.11] (Fig. 5) respectively.

\section{Clinical safety evaluation}

Adverse effects of study drugs were reported as clinical adverse effects. Clinical adverse effects refer to the observable symptoms that occur after taking the medication. The incidence of clinical adverse effects of amoxicillin-clavulanate was significantly higher than that of azithromycin (Table 3). The most common clinical adverse effects observed with both drugs were gastrointestinal disorders (diarrhea, vomiting, nausea, abdominal pain, and loose stool), skin rash, and fever. The metaanalysis on clinical adverse effects showed a statistically significant difference with OR $=0.4695 \%$ CI $(0.33-0.64)$ in favor of amoxicillin/clavuluanate (Fig. 6).

\section{Publication bias}

No publication bias was reported as shown in the funnel plot from STATA.16 depicted in Fig. 7. The included 


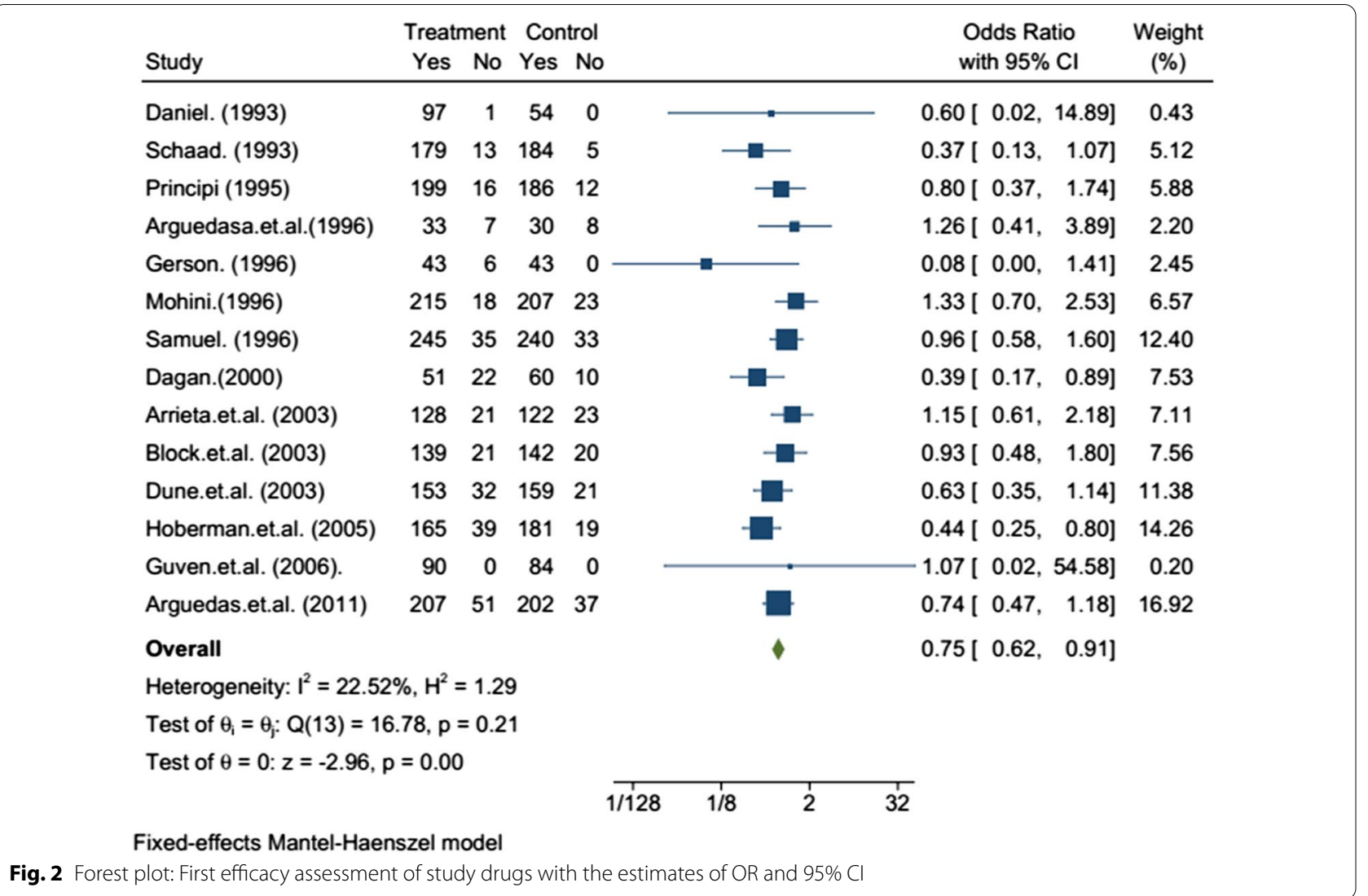

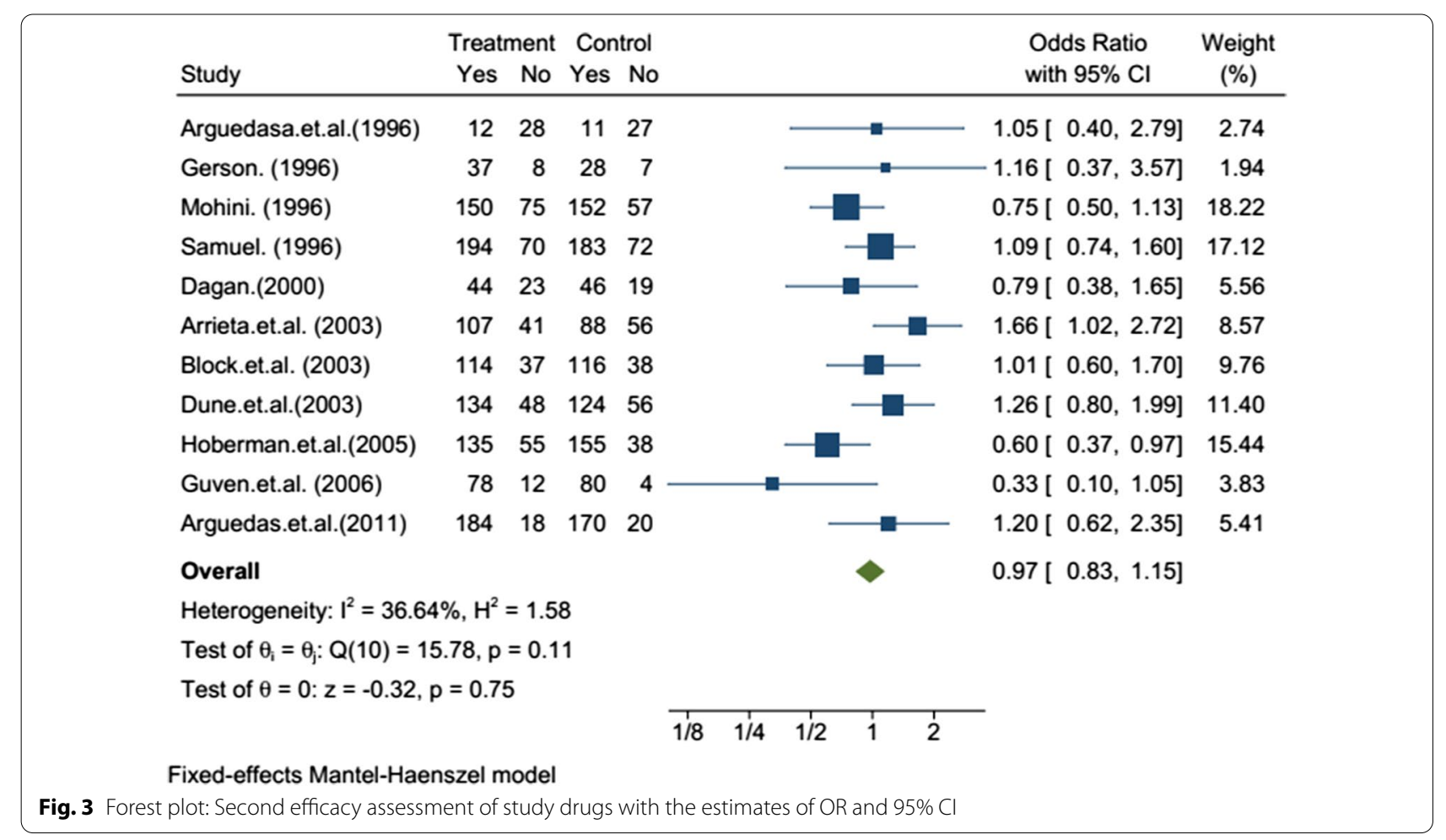




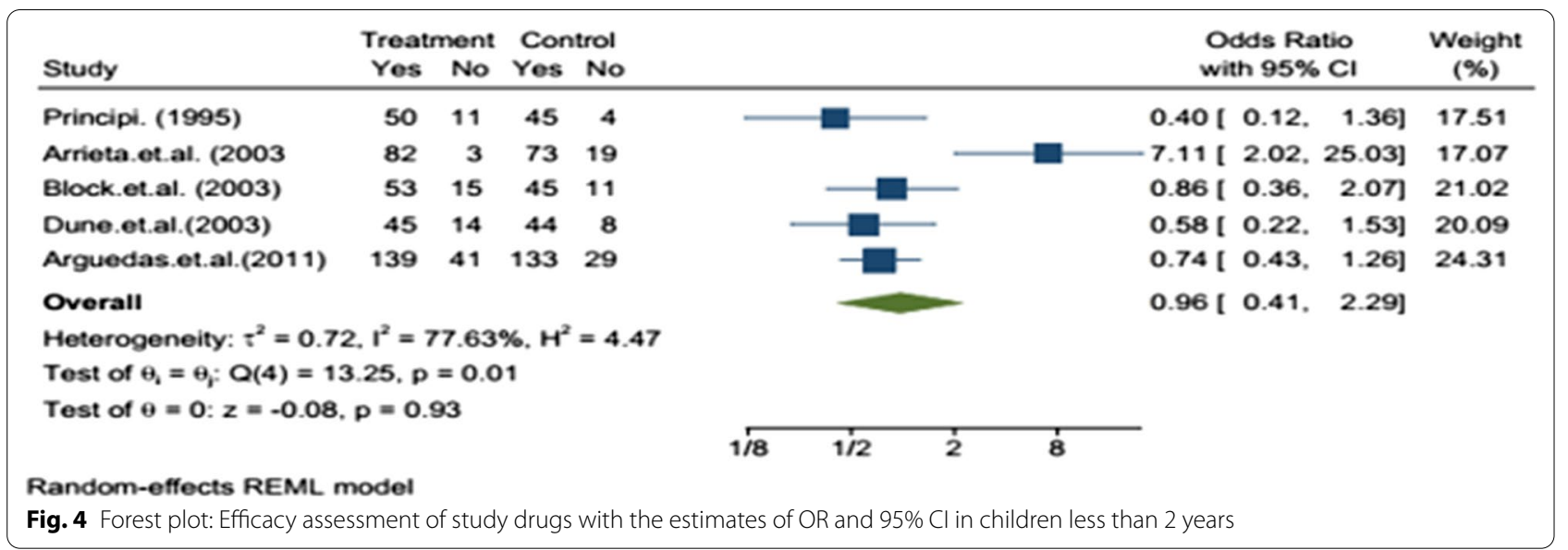

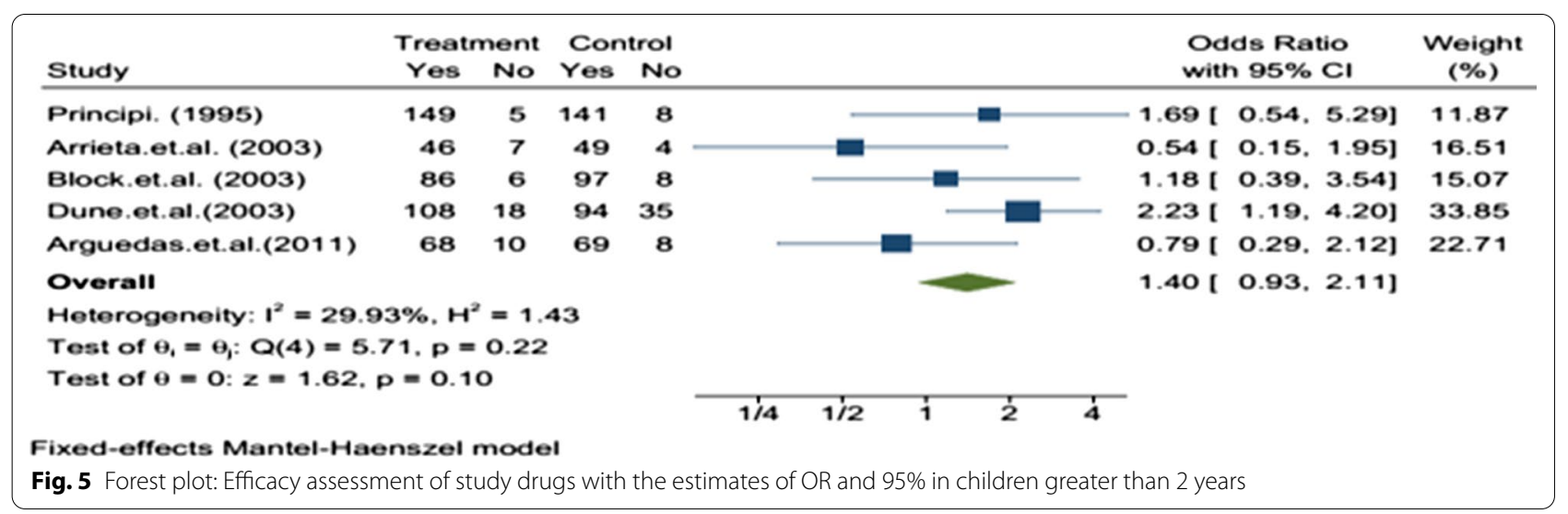

Table 3 Clinical adverse effects of study drugs in children

\begin{tabular}{lccl}
\hline Author (year) & $\begin{array}{l}\text { Azithromycin } \\
\text { group }\end{array}$ & Amox-clav group & P-Value \\
\hline Daniel (1993) & $7.77 \%$ & $3.7 \%$ & $\mathrm{~N} / \mathrm{A}$ \\
Schaad (1993) & $11.7 \%$ & $22.4 \%$ & $<0.002$ \\
Principi (1995) & $4.5 \%$ & $8.3 \%$ & 0.0146 \\
Arguedas et al. (1996) & $17 . \%$ & $66.7 \%$ & $\mathrm{~N} / \mathrm{A}$ \\
Gerson (1996) & $3.5 \%$ & $31 \%$ & $<0.001$ \\
Mohini (1996) & $7.2 \%$ & $17.11 \%$ & $<0.001$ \\
Samuel (1996) & $8.8 \%$ & $32.64 \%$ & $<0.0001$ \\
Dagan (2000) & $21.7 \%$ & $27.12 \%$ & 0.327 \\
Arrieta et al. (2003) & $31.8 \%$ & $42.07 \%$ & 0.095 \\
Block et al. (2003) & $16.8 \%$ & $22.54 \%$ & $\mathrm{NS}$ \\
Dune et al. (2003) & $11.2 \%$ & $20 \%$ & 0.014 \\
Hoberman et al. (2005) & $35.3 \%$ & $37.9 \%$ & $\mathrm{NS}$ \\
Guven et al. (2006) & $4.4 \%$ & $4.76 \%$ & $\mathrm{NS}$ \\
Arguedas et al. (2011) & $45.6 \%$ & $64.16 \%$ & $\mathrm{~N} / \mathrm{A}$ \\
\hline
\end{tabular}

studies are systematically distributed which shows an absence of bias. Three studies have a small size widely scattered at the bottom of the graph with less treatment effect estimation.

\section{Discussion}

In this systematic review and meta-analysis, 14 studies were included. The efficacy evaluation was either clinical or bacteriological efficacy. The clinical efficacy of both study drugs was equivalent with no statistically significant difference in 12 studies. The bacteriological efficacy evaluation of amoxicillin/clavulanate was superior to azithromycin $[16,23]$, but in one of these studies, the dose of amoxicillin was doubled to $90 \mathrm{mg} / \mathrm{kg}$ while that of azithromycin not and in children with no otitis media pathogens there is no significant difference in the clinical efficacy of both drugs [23]. In two studies in all the patients with bacteriological culture-positive test, there is 


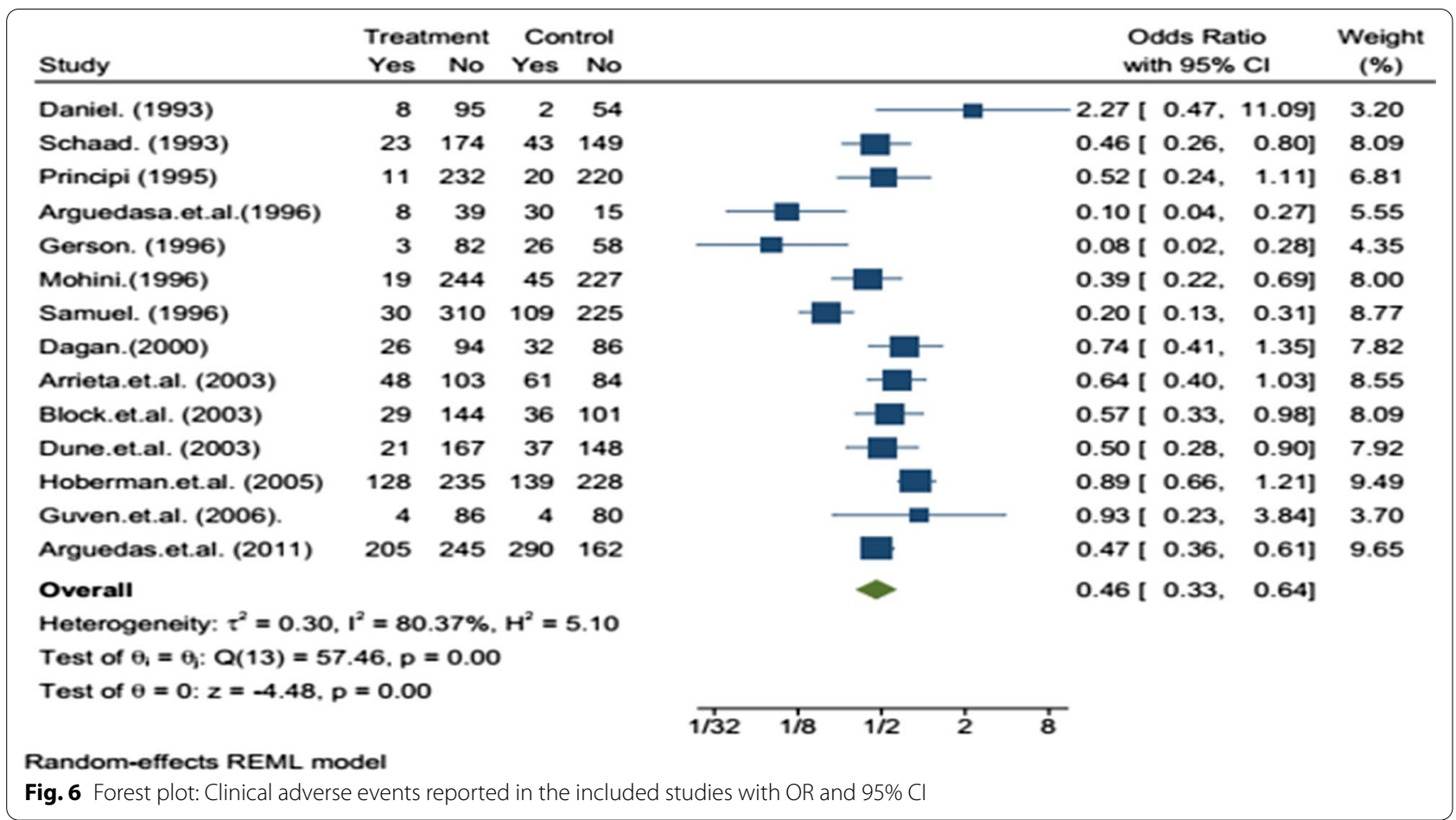

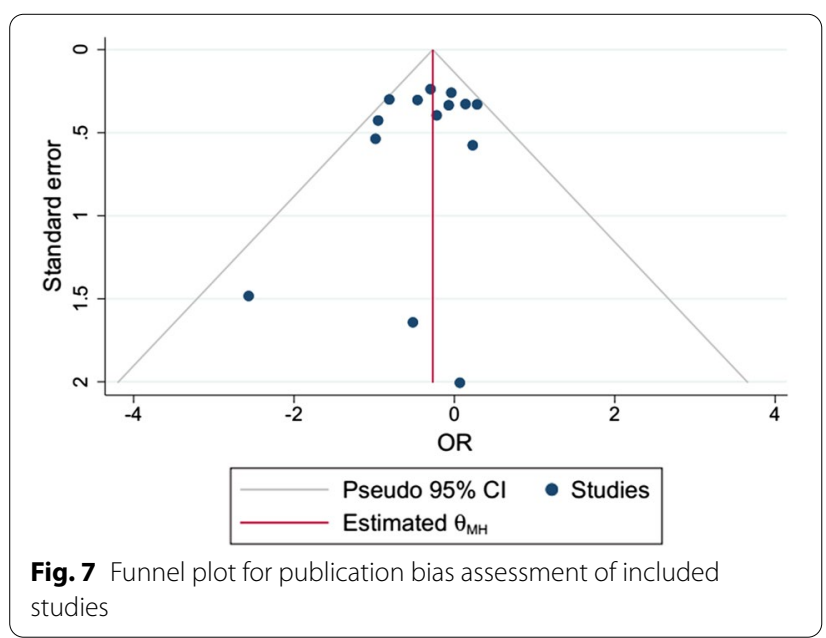

no difference in bacteriologic efficacy of both treatment groups $[20,23]$. In a meta-analysis of a similar study, the bacteriologic efficacy of azithromycin was higher on the treatment of some bacterial respiratory infections on children ( $\mathrm{OR}=0.78,95 \% \mathrm{CI}(0.65-0.93), \mathrm{P}=0.007)$ than that of amoxicillin/ clavulanate [25]. In another similar study which compared 5 days of azithromycin dose, a single intramuscular dose of ceftriaxone and 10 days of amoxicillin/clavulanate dose for treatment of acute otitis media had shown all the equivalent efficacy with $87.1 \%$, $85.3 \%$, and $87.2 \%$ respectively [26]. The failure rates of amoxicillin alone (50 mg/ $\mathrm{kg}$ twice a day for 7 days) and azithromycin (single dose $30 \mathrm{mg} / \mathrm{kg}$ ) for treatment of acute otitis media were $54 \%(83 / 155)$ and $50 \%(82 / 165)$ respectively in another study [27]. In a meta-analysis of 20 RCTs assessed the clinical efficacy of azithromycin and amoxicillin/clavulanate for treatment of upper respiratory infection (acute otitis media and others) in 4980 children, the difference in efficacy was not significant with $\mathrm{OR}=0.7595 \% \mathrm{CI}(0.620 .91) \mathrm{P}$-value 0.003 though the trend was higher with azithromycin [25], while in our meta-analysis the efficacy of both study drugs was comparable with $\mathrm{OR}=0.7595 \% \mathrm{CI}(0.62-0.91)$, but the trend was higher with amoxicillin/clavulanate.

The follow-up efficacy analysis on 21-35 days after treatment initiation was done in 11 studies. In 9 of the studies, the clinical efficacy was not significantly different in both treatment groups. The bacteriological efficacy of amoxicillin/clavuluanate in a single study showed better compared to azithromycin, while no significant difference was observed in the other 3 studies. The difference was smaller than on the first efficacy assessment. In both treatment groups, the efficacy was decreased in comparing with the first efficacy assessment. The efficacy of azithromycin was higher in 6 studies, lower in 4 studies, and equal in one study compared with amoxicillin/clavuluanate. The meta-analysis had shown the efficacy of azithromycin and amoxicillin/ 
clavuluanate on day $21-35$ is equivalent with $\mathrm{OR}=0.97 ; 95 \% \mathrm{CI}(0.83-1.15)$.

The subgroup analysis on the efficacy was also evaluated in less or equal to two and greater than 2 years old children. There was no statistically significant difference in all included 5 studies. The meta-analysis result in less or equal to two and greater than 2 years old children was $\mathrm{OR}=0.96 ; 95 \%$ CI $[0.41-2.29]$ and $\mathrm{OR}=1.4095 \%$ CI [0.93-2.11], respectively. The efficacy of both drugs was a bit higher in children greater than 2 years old children.

Azithromycin is safer and tolerable than amoxicillin/ clavuluanate. The clinical adverse events found in both groups were similar. In our meta-analysis of 14 studies, clinical adverse events were higher with amoxicillin/clavuluanate with $\mathrm{OR}=0.4695 \%$ CI $(0.33-0.64)$. A similar meta-analysis done on $13 \mathrm{RCTs}$ that assessed the safety of azithromycin and amoxicillin/clavuluanate in children with bacterial respiratory infections showed azithromycin was safer with statistically significant difference $(\mathrm{OR}=0.49,95 \%$ CI $(0.40,0.60), \mathrm{P}<0.00001)$ [25] which was quite similar. In another study conducted in children of Australia and New Zealand the adverse effects observed with azithromycin was 17 (21\%) of 82 while with amoxicillin-clavuluanate it was $23(24 \%)$ of $97(\mathrm{RR}=0.9,95 \%$ CI 0.5 to 1.5$)$ [28]. Also, a study by Ferwerda.et.al reported a higher incidence of adverse effects in amoxicillin/clavuluanate than azithromycin $43 \%$ versus $19 \%$, respectively [29]. The most clinical findings observed in both treatment groups were gastrointestinal problems such as vomiting, diarrhea, nausea, and abdominal cramp.

\section{Conclusion}

From the present systematic review and meta-analysis, it can be concluded that the efficacy of azithromycin is comparable to amoxicillin/clavulanate, and it is safer and more tolerable by children. Azithromycin can, also be considered a drug of choice in treatment of otitis media on children.

\section{Acknowledgements}

Authors thank the Center for Innovative Drug Development and Therapeutic Trials for Africa (CDT-Africa) Addis Ababa University for funding this research.

\section{Authors' contributions}

GD (Main researcher), data collection, analysis, and writing manuscript. EM (Advisor), analysis and writing of the manuscript. SM (Co-advisor), analysis and writing of the manuscript. All authors read and approved the final manuscript.

\section{Funding}

This study was funded by the Center for Innovative Drug Development and Therapeutic Trials for Africa (CDT-Africa), Addis Ababa University.

\section{Availability of data and materials}

The sources of data for this systematic review and meta-analysis research are from PubMed, Cochrane library, Google scholar. All the data are available in the following research articles: Arguedas et al. [22] Single-dose extendedrelease azithromycin versus a 10-day regimen of amoxicillin/clavuluanate for the treatment of children with acute otitis media International Journal of Infectious Diseases 15; e240-e248 https://doi.org/10.1016/j.ijid.2010.12.003. Arguedas et al. [13] Comparative trial of 3-day azithromycin versus 10-day amoxicillin/clavuluanate potassium in the treatment of children with otitis media with effusion. International Journal of Antimicrobial Agents 6; 233-238. Arrieta and Singh [6] Management of recurrent and persistent acute otitis media: new options with familiar antibiotics. Pediatric Infectious Disease Journal; 23 (2):115-124. Block et al. [19] Single-dose (30 mg/kg) azithromycin compared with 10-day amoxicillin/clavuluanate for the treatment of uncomplicated acute otitis media: a double-blind, placebo-controlled, randomized clinical trial. Current Therapeutic Research 64: A30-A40. https://doi.org/ 10.1016/j.curtheres.2003.09.006. Dagan et al. [21] Bacteriologic and clinical efficacy of amoxicillin/clavuluanate $v$ s. azithromycin in acute otitis media. Pediatric Infectious Diseases Journal. 19 (2):95-104. Daniel et al. [30] Comparison of azithromycin and co-amoxiclav in the treatment of otitis media in children Journal of Antimicrobial Chemotherapy. 31, E, 65-71. Gerson [20]. A multicenter open label trial of azithromycin versus amoxicillin/clavulanate for the management of acute otitis media in children. Pediatric Infectious Diseases Journal 15 (6) 15-19. Guven et al. [16] Bacterial etiology of acute otitis media and clinical efficacy of amoxicillin - clavuluanate versus azithromycin. International Journal of Pediatric Otorhinolaryngology: 70: 915-923. Hoberman et al. [23]. Large dosage amoxicillin/clavuluanate, compared with azithromycin, for the treatment of bacterial acute otitis media in children. Pediatric Infectious Diseases Journal. 24 (6): 525-532. https://doi.org/10.1097/01.inf.0000164794. 50281.1a. Mohini [17]. A multicenter randomized open-label comparison of azithromycin and amoxicillin/clavuluanate in acute otitis media among children attending daycare or school. Pediatric Infectious Diseases Journal. 15 (09): 24-29. Principi [24]. Multicenter comparative study of the efficacy and safety of azithromycin compared with amoxicillin/clavulanic acid in the treatment of pediatric Patients with Otitis Media. European Journal of Clinical Microbiology and Infectious Diseases. 14 (8):669-676. Samuel [14]. A multi-center double blind comparison of azithromycin and amoxicillin- clavuluanate for the treatment of acute otitis media in children. Pediatric Infectious Diseases Journal. 15(9):20-23. Schaad [31]. Multicenter evaluation of azithromycin in comparison with co-amoxiclav for the treatment of acute otitis media in children. Journal of Antimicrobial Chemotherapy: 31: 81-88.

\section{Declarations}

Ethics approval and consent to participate Not applicable.

\section{Consent for publication}

All authors gave their consent for this research article to be published in Annals of Clinical Microbiology and Antimicrobials.

\section{Competing interests}

Authors have no conflict of interest in this study.

\section{Author details}

${ }^{1}$ Center for Innovative Drug Development and Therapeutic Trials for Africa (CDT Africa), College of Health Sciences, Addis Ababa University, Addis Ababa, Ethiopia. ${ }^{2}$ Department of Pharmacology and Clinical Pharmacy, College of Health Sciences, Addis Ababa University, Addis Ababa, Ethiopia.

Received: 24 February 2021 Accepted: 16 April 2021

Published online: 24 April 2021

\section{References}

1. Scottish intercollegiate guidelines network, diagnosis and management of childhood otitis media in primary care, a national clinical guideline. 2003. ISBN 1899893482 www.sign.ac.uk.

2. World Health Organization. Primary ear and hearing care training resource; 2006. http://www.who.int.pbd. 
3. Penido NO, et al. Complications of otitis media-a potentially lethal problem still present. Braz J Otorhinolaryngol. 2016;82:253-62. https://doi.org/10 1016/j.bjorl.2015.04.007.

4. Harmes $\mathrm{K}$, et al. Otitis media: diagnosis and treatment. Am Family Phys. 2013;88(7):435-531.

5. Jacobs MR, et al. Prevalence of antimicrobial-resistant pathogens in middle ear fluid. Antimicrob Agents Chemother. 1998;42(3):589-95.

6. Arrieta A, Singh J. Management of recurrent and persistent acute otitis media: new options with familiar antibiotics. Pediatric Infect Dis J. 2004;23(2):115-24.

7. Schilder GM, et al. Otitis media. Nat Rev Dis Primer. 2016;2:1-18. https://doi. org/10.1038/nrdp.2016.63.

8. DeAntonio $\mathrm{R}$, et al. Epidemiology of otitis media in children from developing countries: a systematic review. Int J Pediatr Otorhinolaryngol. 2016;8:565-74.

9. Klein JO. The burden of otitis media. Vaccine. 2000;19(1):2-8.

10. Pechère JC. The activity of azithromycin in animal models of infection. Eur Clin Microbiol Infect Dis. 1991;10(10):821-7. https://doi.org/10.1007/bf019 75834.

11. Baldwin RL. Effects of otitis media on child development. Am J Otolaryngol. 1993;14(6):601-4.

12. Liberati A, et al. The PRISMA Statement for Reporting Systematic Reviews and Meta-Analyses of Studies that evaluate health care interventions: explanation and elaboration. PLoS Med. 2009:6(7):e1000100.

13. Arguedas A, et al. Comparative trial of 3-day azithromycin versus 10-day amoxicillin/clavuluanate potassium in the treatment of children with otitis media with effusion. Int J Antimicrob Agents. 1996;6:233-8

14. Samuel M. A multi-center double-blind comparison of azithromycin and amoxicillin- clavuluanate for the treatment of acute otitis media in children. Pediatric Infect Dis J. 1996;15(9):20-3.

15. Dunne MW, et al. Randomized, double-blind study of the clinical efficacy of 3 days of azithromycin compared with co-amoxiclav for the treatment of acute otitis media. J Antimicrob Chemother. 2003;52:469-72. https://doi. org/10.1093/jac/dkg358.

16. Guven $\mathrm{M}$, et al. Bacterial etiology of acute otitis media and clinical efficacy of amoxicillin—clavuluanate versus azithromycin. Int J Pediatr Otorhinolaryngol. 2006;70:915-23.

17. Mohini KC. A multicenter randomized open-label comparison of azithromycin and amoxicillin/clavuluanate in acute otitis media among children attending daycare or school. Pediatric Infect Dis J. 1993:15(09):24-9.

18. Arrieata $A$, et al. High-dose azithromycin versus high-dose amoxicillinclavulanate for treatment of children with recurrent or persistent acute otitis media. Antimicrob Agents Chemother. 2003;47(10):3179-86.

19. Block SL, et al. Single-dose ( $30 \mathrm{mg} / \mathrm{kg}$ ) azithromycin compared with 10-day amoxicillin/clavuluanate for the treatment of uncomplicated acute otitis media: a double-blind, placebo-controlled, randomized clinical trial. Curr Ther Res. 2003;6(4):A30-40. https://doi.org/10.1016/j.curtheres.2003.09.006.
20. Gerson A. A multicenter open-label trial of azithromycin versus amoxicillin/ clavulanate for the management of acute otitis media in children. Pediatric Infect Dis J. 1996;15(6):15-9.

21. Dagan $R$, et al. Bacteriologic and clinical efficacy of amoxicillin/clavuluanate vs. azithromycin in acute otitis media. Pediatric Infect Dis J. 2000;19(2):95-104

22. Arguedas $A$, et al. Single-dose extended-release azithromycin versus a 10-day regimen of amoxicillin/clavuluanate for the treatment of children with acute otitis media. Int J Infect Dis. 2011;15:e240-8. https://doi.org/10. 1016/j.ijid.2010.12.003.

23. Hoberman A, et al. Large dosage amoxicillin/clavuluanate, compared with azithromycin, for the treatment of bacterial acute otitis media in children. Pediatric Infect Dis J. 2005;24(6):525-32. https://doi.org/10.1097/01.inf.00001 64794.50281.1a.

24. Principi N. Multicenter comparative study of the efficacy and safety of azithromycin compared with amoxicillin/clavulanic acid in the treatment of pediatric Patients with Otitis Media. Eur J Clin Microbiol Infect Dis. 1995;14(8):669-76.

25. Wang PX, et al. Clinical efficacy and safety of azithromycin versus amoxicillin-clavulanic acid in the treatment of some acute respiratory infections in children. Int J Pharm Res. 2016;210(4):646-51. https://doi.org/10.13220/j. cnki.jipr.2016.04.011.

26. Binner B, et al. The comparison of single-dose ceftriaxone, five-day azithromycin, and ten-dayamoxicillin/clavuluanate for the treatment of children with acute otitis media. Turkey J Pediatrics. 2007;49(4):390-6.

27. Morris PS, et al. Single-dose azithromycin versus seven days of amoxicillin in the treatment of acute otitis media in Aboriginal children (AATAAC): a double-blind, randomized controlled trial. Medical J. 2010;192(1):24-9.

28. Goyal V, et al. Efficacy of oral amoxicillin/clavuluanate or azithromycin for non-severe respiratory exacerbation in children with bronchiectasis (BEST1): a multicenter, three-arm, double-blind randomized placebo-controlled trial. Lancet Resp Med. 2019;7(9):791-801. https://doi.org/10.1016/S22132600(19)30254-1.1.

29. Ferwerda A, et al. Efficacy safety and tolerability 3-day azithromycin versus 10-day co-amoxiclav in the treatment of children with acute lower respiratory tract infection. J Antimicrob Therapy. 2001;47:441-6.

30. Daniel RR, et al. Comparison of azithromycin and co-amoxiclav in the treatment of otitis media in children. J Antimicrob Chemother. 1993;31(Suppl_E):65-71.

31. Schaad UB. Multicenter evaluation of azithromycin in comparison with coamoxiclav for the treatment of acute otitis media in children. J Antimicrob Chemother. 1993:31:81-8.

\section{Publisher's Note}

Springer Nature remains neutral with regard to jurisdictional claims in published maps and institutional affiliations.
Ready to submit your research? Choose BMC and benefit from:

- fast, convenient online submission

- thorough peer review by experienced researchers in your field

- rapid publication on acceptance

- support for research data, including large and complex data types

- gold Open Access which fosters wider collaboration and increased citations

- maximum visibility for your research: over 100M website views per year

At $\mathrm{BMC}$, research is always in progress.

Learn more biomedcentral.com/submissions 